\title{
Early transcriptional response in the jejunum of germ-free piglets after oral infection with virulent rotavirus
}

\author{
Marcel Hulst · Hinri Kerstens · Agnes de Wit • \\ Mari Smits · Jan van der Meulen · Theo Niewold
}

Received: 7 December 2007 / Accepted: 16 May 2008/Published online: 4 June 2008

(C) The Author(s) 2008

\begin{abstract}
Germ-free piglets were orally infected with virulent rotavirus to collect jejunal mucosal scrapings at 12 and 18 hours post infection (two piglets per time point). IFNgamma mRNA expression was stimulated in the mucosa of all four infected piglets, indicating that they all responded to the rotavirus infection. RNA pools prepared from two infected piglets were used to compare whole mucosal gene expression at 12 and $18 \mathrm{hpi}$ to expression in uninfected germ-free piglets $(n=3)$ using a porcine intestinal cDNA microarray. Microarray analysis identified 13 down-regulated and 17 up-regulated genes. Northern blot analysis of a selected group of genes confirmed the data of the microarray. Genes were functionally clustered in interferon-regulated genes, proliferation/differentiation genes, apoptosis genes, cytoskeleton genes, signal transduction genes, and enterocyte digestive, absorptive, and transport genes. Downregulation of the transport gene cluster reflected in part the loss of rotavirus-infected enterocytes from the villous tips. Data mining suggested that several genes were regulated in lower- or mid-villus immature enterocytes and goblet cells, probably to support repair of the damaged epithelial cell layer at the villous tips. Furthermore, up-regulation was
\end{abstract}

Electronic supplementary material The online version of this article (doi:10.1007/s00705-008-0118-6) contains supplementary material, which is available to authorized users.

M. Hulst $(\bowtie) \cdot$ H. Kerstens · A. de Wit · M. Smits ·

J. van der Meulen $\cdot$ T. Niewold

Animal Sciences Group of Wageningen University and Research

Center, P. O. Box 65, 8200 AB Lelystad, The Netherlands

e-mail: marcel.hulst@wur.nl

Present Address:

T. Niewold

Katholieke Universiteit Leuven, Kasteelpark Arenberg 30,

Leuven 3001, Belgium observed for IFN- $\gamma$ induced guanylate binding protein 2 , a protein that effectively inhibited VSV and EMCV replication in vitro (Arch Virol 150:1213-1220, 2005). This protein may play a role in the small intestine's innate defense against enteric viruses like rotavirus.

\section{Introduction}

With an estimated death rate of more than 400,000 per year, mainly affecting children less than 5 years of age in developing countries, rotavirus is recognized as one of the major infectious diseases of the gastrointestinal tract [38]. Rotaviruses are members of the family Reoviridae, viruses with segmented double-stranded RNA genomes [17].

In the small intestine, mature enterocytes near the top of the villi are the primary target cells for virus replication [29]. Replication in these cells provokes numerous intraand extracellular pathological changes that inevitably lead to disruption of the absorptive and digestive functions of the small intestine, and consequently, to malabsorption and diarrhea. These changes include destruction of enterocyte brush borders, enterocyte vacuolization, loss and destruction of enterocytes, villus blunting and atrophy, thinning of the intestinal wall, and crypt hyperplasia (for comprehensive reviews, see [29, 39]). However, the nature and severity of histopathological alterations in vivo can be quite different depending on the species and virulence of the rotavirus strain. There is no clear correlation between these alterations and manifestation of clinical symptoms. A systemic inflammatory response can be absent, and rotavirus infections can be asymptomatic [29, 39]. This suggests that the interplay between host and viral factors is important for determining the course of this disease. For 
instance, rotavirus NSP4 acts as an enterotoxin that induces diarrhea in mice in the absence of rotavirus replication [5]. NSP4 affects $\mathrm{Ca}^{2+}$ and electrolyte homeostasis in an auto- and paracrine fashion in both rotavirus-infected and uninfected intestinal cells [41]. NSP4 increases $\mathrm{Ca}^{2+}$ permeability of the ER and plasma membrane, resulting in an increased $\mathrm{Ca}^{2+}$ concentration in the cytosol $\left(\left[\mathrm{Ca}^{2+}\right]_{\text {cyt }}\right)$, causing derailment of numerous $\mathrm{Ca}^{2+}$-dependent cellular processes [40]. In uninfected enterocytes and crypt cells this rise in $\left[\mathrm{Ca}^{2+}\right]_{\mathrm{cyt}}$ is induced by binding of exogenous NSP4 to an apical receptor that modulates the PLC-IP 3 pathway [16]. The higher $\left[\mathrm{Ca}^{2+}\right]_{\mathrm{cyt}}$ triggers laminal secretion of peptides and amines by uninfected enterocytes, and luminal $\mathrm{Cl}^{-}$and $\mathrm{H}_{2} \mathrm{O}$ secretion by crypt cells [28, 39]. In infected enterocytes, the rise in $\left[\mathrm{Ca}^{2+}\right]_{\text {cyt }}$ is believed to be independent of PLC modulation [41], and this rise perturbs cytoskeleton and tight junction integrity, which ultimately leads to cell lysis [9, 10, 26, 37].

In vitro studies with cell lines, mainly derived from colon, have contributed significantly toward understanding the pathogenesis of rotavirus on a molecular level. However, the intestinal mucosa consists of a diversity of specialized cell types in different states of differentiation. Presumably, all these different types of cells respond differently to environmental changes, and accordingly to changes in their neighboring cells. Therefore, the regulation of genes responsible for these complex phenotypic responses in vivo may not be detected by challenging single types of cultured cells with rotavirus. To address this issue, we studied the early transcriptional response in jejunal mucosa of 3-week-old, just-weaned piglets after oral infection with virulent group A rotavirus. To assign measured responses exclusively to rotavirus, we performed these experiments in germ-free piglets. Differential expression patterns of uninfected versus infected jejunum were recorded 12 and $6 \mathrm{~h}$ before severe diarrhea was expected, using a homemade pig intestinal cDNA microarray [34]. The biological significance of elevated or reduced expression of these genes for rotavirus pathogenesis is discussed.

\section{Materials and methods}

\section{Animal experiment}

Seven germ-free piglets (Groot Yorkshire $\times$ [Cofok $\times$ Large White]) were obtained by caesarean section and housed in isolators, fed with sterilized condensed milk till the age of 14 days and thereafter with pelleted feed (sterilized by X-ray radiation) and water ad lib. On day 21 , three of the seven piglets were transported to the necropsy room and served as uninfected control piglets.
The four remaining pigs were orally infected with virus suspension diluted in a total volume of $5 \mathrm{ml}$ PBS and containing $2 \times 10^{7}$ rotavirus particles (as determined by negative-stain semi-quantitative electron microscopy) of strain RV277 [45]. The virus suspension was prepared from the contents of the small and large intestine of a rotavirus-infected gnotobiotic piglet [32]. The above applied oral dose caused severe diarrhea from 24 hpi (hours post infection) in 3-week-old gnotobiotic piglets [32]. Infected piglets were housed in their isolators under the same conditions as described above for another period of 12 (two piglets) or $18 \mathrm{~h}$ (two piglets) before they were transported to the necropsy room. Immediately after arrival in the necropsy room, $10 \mathrm{ml}$ of EDTA blood for hematological analysis was collected from the jugular vein. Subsequently, animals were killed by barbiturate overdose and their intestines were taken out. The jejunum was opened and rinsed with cold saline, and $10 \mathrm{~cm}$ of mucosa in the middle of the jejunum was scraped off with a glass slide, frozen in liquid nitrogen, and kept at $-70^{\circ} \mathrm{C}$ until RNA and DNA extraction. An adjacent part of the collected jejunum was fixed in $4 \%$ formaldehyde and used to determine the villus height and crypt depth. Villus and crypt dimensions were determined on hematoxylin-eosinstained 5- $\mu \mathrm{m}$ tissue sections [34]. During the experiment, fecal samples were collected at 0,12 and 18 hpi from the rectum for determination of the percent dry matter [18]. Fecal samples were tested for the presence or absence of rotavirus by ELISA [33]. The germ-free status of each piglet was confirmed by analyzing throat saliva and feces samples, collected on days 6,12 and 19, and on the day of slaughter, for the presence of microorganisms.

\section{Isolation of RNA and DNA}

From $1 \mathrm{~g}$ of frozen mucosal scrapings, total RNA (DNasefree) was isolated using TRIzol ${ }^{\circledR}$ reagent (Invitrogen) as described recently [34]. The yield per gram of tissue and the purity of the RNA were calculated from measurement of the extinction at 260 and $280 \mathrm{~nm}$. The integrity of all RNA samples was checked by analyzing $5 \mu \mathrm{g}$ of RNA on a denaturizing $1 \%(\mathrm{w} / \mathrm{v})$ agarose gel. After ethidium bromide staining, the gel was scanned to calculate the $28 \mathrm{~S} / 18 \mathrm{~S}$ peak ratio (volume $28 \mathrm{~S}$ over volume $18 \mathrm{~S}$ ) for each preparation. RNA with a ratio $>2$ was considered of adequate quality to be used for real-time PCR and microarray analysis. A part of the isolated RNA was used to prepare RNA pools for microarray analysis. A control pool was prepared by mixing equal amounts of RNA isolated from the jejunum of the three uninfected piglets $(n=3)$. The same was done for the two infected piglets slaughtered at $12 \mathrm{~h}$ and for the two piglets slaughtered at $18 \mathrm{~h}$. After gentle homogenization in lysis buffer, DNA was extracted from $0.5 \mathrm{~g}$ of frozen 
mucosal scrapings, and $4 \mu \mathrm{g}$ of purified DNA was analyzed on a $0.9 \%$ agarose gel [22].

\section{Real-time PCR}

The relative concentrations of interferon-gamma (IFN- $\gamma$ ) and ornithine decarboxylase antizyme 1 (OAZ1) mRNA in all RNA samples was determined by real-time PCR. Two hundred ng of total RNA was reverse transcribed in a standard RT reaction using Superscript II reverse transcriptase (Invitrogen) and $\mathrm{pd}(\mathrm{N})_{6}$ primers. IFN- $\gamma$ cDNA in these RT reactions was quantified using labeled LightCycler probes (Roche Diagnostics) as described [15] and expressed as $\mathrm{pg} / \mu \mathrm{l}$ control plasmid. A 20-mer forward primer (5'-GACCCGACGCTTGCTTCATG-3') and a 19mer reverse primer $\left(5^{\prime}\right.$-GAGTGAGCGTTTATTTGCAC$3^{\prime}$ ), generating a cDNA fragment homolog to nucleotide 702-895 of the human OAZ1 mRNA reference sequence (gi:34486089), were used to quantify OAZ1 cDNA using Cybergreen as label in a standard LightCycler reaction. The relative concentration of OAZ1 mRNA was calculated by extrapolation on a standard curve prepared from dilutions of an RT reaction prepared from a reference RNA sample [34]. The quantity of $18 \mathrm{~S}$ rRNA in each RNA sample was determined using the above described RT reactions by real-time PCR [15] and used to normalize the IFN- $\gamma$ and OAZ1 concentrations. The quantity of $18 \mathrm{~S}$ rRNA showed no essential differences among all individual RNA samples (average concentration $\pm \mathrm{SD} ; 4.95 \pm$ $0.82 \mu \mathrm{g} / \mu \mathrm{l}$ of control plasmid).

\section{Microarray analysis}

The same collection of pig probes (ESTs) used in earlier studies [34, 35] were spotted in triplicate on Corning UltraGAPS slides. Briefly, this collection consisted of 2,928 probes prepared from jejunal mucosal scrapings collected from 4-week- (672) and 12-week- $(2,256)$ old pigs, probes coding for porcine cytokines (IFN- $\gamma$, TNF- $\alpha$, GMCSF, IL$2,4,6,8$, and 10) and lung surfactant proteins SFTPA and SFTPD, and 110 Marc1 and Marc2 probes (porcine ESTs) homolog to trefoils, collectins, defensins, and glycosyltransferases [34]. A list of the probes already sequenced/ annotated is accessible on the website of Arch Virol (gene list Hulst et al. pdf).

Dual-color (Cy3-Cy5) hybridization of slides was performed using the RNA MICROMAX TSA labeling and detection kit (PerkinElmer) as described earlier [34]. Messenger RNA levels in both infected pools (12 and $18 \mathrm{hpi}$ ) were independently compared to the expression levels in the control (uninfected) pool. For each comparison, a dye swap was performed. In addition, a control hybridization experiment was performed in which a microarray slide was simultaneously hybridized with Cy3labeled control RNA and Cy5-labeled control RNA. Scanning of slides, processing of raw images, creation of data reports, data-normalization and statistical analysis were performed as described by Niewold et al. [34] with minor modifications. Briefly, probes were considered to be differentially expressed when at least four of the six data points (spots) on both dye swap slides hybridized with a ratio of 3.6-fold $\left(M=\left[\log _{2}(\mathrm{Cy} 3 / \mathrm{Cy} 5)\right]<-1.85\right.$ or $\left.>1.85\right)$ or more (3.6 is considered significant according to the manufacturer of the TSA kit) and were identified by significant analysis of microarrays (SAM) [43] with a median false discovery rate (FDR or $q$ value) of $<5 \%$.

\section{Northern blot analysis}

Equal amounts of total RNA $(5 \mu \mathrm{g})$ were separated on a denaturizing $1 \%(\mathrm{w} / \mathrm{v})$ agarose gel. After several washes with RNase-free water, the gel was blotted on Hybond-N membranes (Amersham), and blots were hybridized with ${ }^{32}$ P-labeled DNA fragments homolog to the mRNA in question, in the same manner as was described in an earlier study [34]. After post-hybridization washes, the blots were scanned using a Storm phosphor-imager (Molecular Dynamics, Sunnyvale, California, USA).

\section{Results}

Infection of germ-free piglets with rotavirus

Four 3-week-old germ-free piglets were orally infected with a dose of rotavirus that caused severe diarrhea from 24 hpi in 3 -week-old gnotobiotic piglets [32]. For practical reasons, three uninfected germ-free piglets were slaughtered at the zero time point (mock, see Table 1). In order to isolate highquality RNA from jejunal mucosal scrapings, infected piglets were slaughtered 12 and 18 hpi. Thus, 12 and $6 \mathrm{~h}$ before severe diarrhea would have been induced. In three of the four infected animals, rotavirus was detected in their feces. Determination of the percent dry matter showed that only the fecal samples collected 18 hpi (piglets 65 and 67) had a significantly lower (pasty) consistency [18]. This indicated that not all of the piglets developed diarrhea before $12 \mathrm{hpi}$, and that the two piglets slaughtered 18 hpi did not develop the severe form of diarrhea normally observed at $24 \mathrm{hpi}$ [32]. In jejunal tissue sections prepared from these two 18-h piglets, villus length was decreased to two-thirds of the average length measured in corresponding sections prepared from the three control piglets. No significant differences in crypt depths were observed between infected and control animals. For both piglets that were slaughtered at $18 \mathrm{~h}$, these results indicated that the orally applied rotavirus reached the 
Table 1 Infection of piglets with rotavirus

\begin{tabular}{|c|c|c|c|c|c|c|c|c|c|c|c|c|}
\hline \multirow[t]{3}{*}{ Piglet } & \multirow{3}{*}{$\begin{array}{l}\text { Slaugther } \\
\text { hpi. }\end{array}$} & \multirow{2}{*}{\multicolumn{3}{|c|}{$\begin{array}{l}\text { Faces }^{\mathrm{a}} \\
\% \text { Dry matter/rota } \\
\text { virus ELISA }\end{array}$}} & \multirow{2}{*}{\multicolumn{3}{|c|}{$\frac{\mathrm{WBC}^{\mathrm{b}}}{\left(10^{9} \text { per } 1\right) \% \text { Lympho/mon. and gran. }}$}} & \multicolumn{5}{|l|}{ Jejunum $^{c}$} \\
\hline & & & & & & & & \multirow[t]{2}{*}{$\begin{array}{l}\text { Villus } \mu \mathrm{m} \\
\text { heigth }\end{array}$} & \multirow[t]{2}{*}{$\begin{array}{l}\text { Crypt } \mu \mathrm{m} \\
\text { dept }\end{array}$} & \multirow[t]{2}{*}{$\begin{array}{l}\mathrm{V} / \mathrm{C} \\
\text { ratio }\end{array}$} & \multicolumn{2}{|l|}{ RNA } \\
\hline & & 0 hpi & 12 hpi & 18 hpi & 0 hpi & $12 \mathrm{hpi}$ & $18 \mathrm{hpi}$ & & & & $\begin{array}{l}\text { Yield } \\
(\mathrm{mg} / \mathrm{g})\end{array}$ & $\begin{array}{l}28 \mathrm{~S} / 18 \mathrm{~S} \\
\text { Ratio }\end{array}$ \\
\hline 62 Mock & 0 & $20.4 /-$ & NA & NA & (4.8) $71 / 29$ & NA & NA & 654 & 85 & 7.7 & 0.78 & 5.1 \\
\hline 78 Mock & 0 & $19.2 /-$ & NA & NA & (3.1) $71 / 29$ & NA & NA & 485 & 75 & 6.5 & 0.84 & 4.0 \\
\hline 85 Mock & 0 & $21.4 /-$ & NA & NA & 56/44 (3.9) & NA & NA & 531 & 79 & 6.7 & 0.84 & 4.4 \\
\hline 63 Rota & 12 & $17.3 /-$ & $17.9 /-$ & NA & (8.5) $75 / 25$ & (2.8) 61/39 & NA & 416 & 77 & 5.4 & 0.67 & 3.9 \\
\hline 64 Rota & 12 & $21.6 /-$ & $20.4 /+$ & NA & (5.5) $67 / 33$ & (3.1) $58 / 42$ & NA & 482 & 88 & 5.5 & 0.65 & 4.1 \\
\hline 65 Rota & 18 & $18.9 /-$ & $20.6 /-$ & $16.5 /+$ & 64/36 (9.1) & 70/30 & 23/77 (3.1) & 355 & 78 & 4.6 & 0.90 & 4.2 \\
\hline 67 Rota & 18 & $18.8 /-$ & $19.8 /-$ & $12.4 /+$ & (7.5) $65 / 35$ & (5.8) 62/38 & 11/89 (1.8) & 354 & 78 & 4.5 & 1.09 & 3.7 \\
\hline
\end{tabular}

a The consistency of the feces was classified [18] as normal, unformed or loose, pasty, or fluid, by determining the percent dry matter (\% dm). Feces samples were tested for the presence of rotavirus by ELISA [33]. NA not available

${ }^{b}$ White blood cells were counted $\left(10^{9}\right.$ per 1$)$ and the percent lymphocytes and the percent monocytes plus granulocytes were determined

c Villus height $(\mu \mathrm{m})$ and crypt dept $(\mu \mathrm{m})$ were determined on hematoxylin-eosin-stained 5- $\mu \mathrm{m}$ tissue sections. $V / C$ ratio villus height over crypt depth. Ratios of $28 \mathrm{~S} / 18 \mathrm{~S}$ ribosomal RNA peak volumes were established by scanning of an ethidium-bromide-stained denaturizing $1 \%$ (w/v) agarose gel

jejunum and induced the desired limited (not severe) pathological symptoms. In addition, the lower concentration of lymphocytes in the blood indicated that the animals were effectively infected with rotavirus [47].

In the feces of piglet 63, slaughtered at $12 \mathrm{~h}$, no rotavirus could be detected. Moreover, only a small decrease in villus length (20\%) was observed for this piglet and its 12-h replicate. To find additional evidence whether the jejunum of piglet 63 was effectively challenged with rotavirus, the level of IFN- $\gamma$ mRNA in jejunal mucosal scrapings was measured by real-time PCR (Fig. 1). In RNA samples isolated from the three uninfected pigs, hardly any IFN- $\gamma$ mRNA could be detected. In contrast, the IFN- $\gamma$ mRNA levels in scrapings of all infected piglets were up to 50-fold higher than in

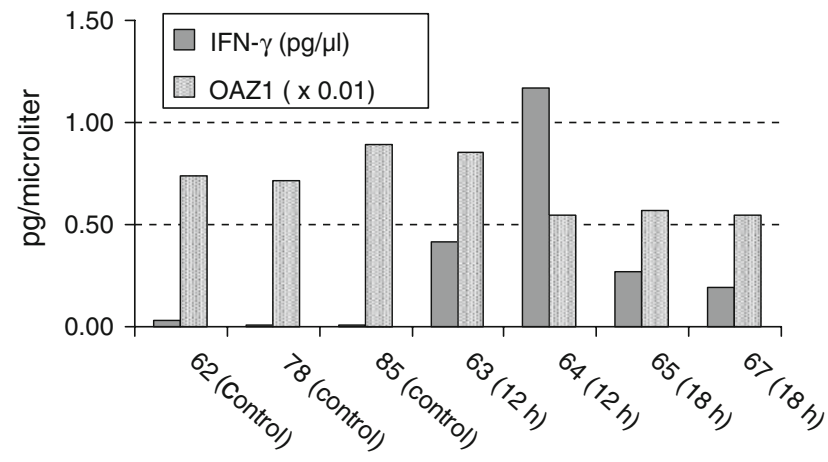

Fig. 1 Quantification of IFN- $\gamma$ and OAZ-1 mRNA in individual RNA samples by real-time PCR. IFN- $\gamma$ levels are expressed in $\mathrm{pg} / \mu \mathrm{l}$ of control PCR plasmid. The $Y$-axis values for OAZ-1 mRNA are given in arbitrary units and divided by 100 to match values of the $Y$-axis uninfected piglets, whereas OAZ1 mRNA levels were nearly equal for all RNA samples. This indicated that the jejunum of all piglets, including piglet 63 , responded to the orally applied rotavirus challenge.

Despite the loss of cells from the tip of the villi, the amount of RNA (Table 1) isolated from all infected piglets was comparable to that of uninfected piglets. On an ethidium-bromide-stained agarose gel, no degradation of RNA was visible for any of the extracted RNA samples (see also Fig. 2a). In addition, 28S/18S peak ratios were $>2$ for all these samples (Table 1). These results showed that scrapings collected from all piglets yielded high-quality RNA suitable for real-time PCR and microarray analysis. No random (necrotic) and/or fragmentized (apoptotic) DNA was visible after gel electrophoreses of DNA samples extracted from any of the piglets, indicating that the majority of cells imbedded in the epithelial layers of all the piglets were not apoptotic or necrotic (results not shown).

\section{Microarray analysis}

Mid-jejunal mucosal gene expression analysis was performed using a homemade pig cDNA small intestinal microarray [34]. In two separate hybridization experiments, mRNA expression levels in an uninfected RNA pool $(n=3)$ were compared to expression levels in RNA pools prepared from 12- and 18-h infected piglets (both $n=2$ ). For both comparisons, dye swaps were performed. Probes that hybridized differentially with a ratio (FC; infected over uninfected) of $<0.28$ or $>3.6$ in both slides of the dye-swap and that were identified with the 

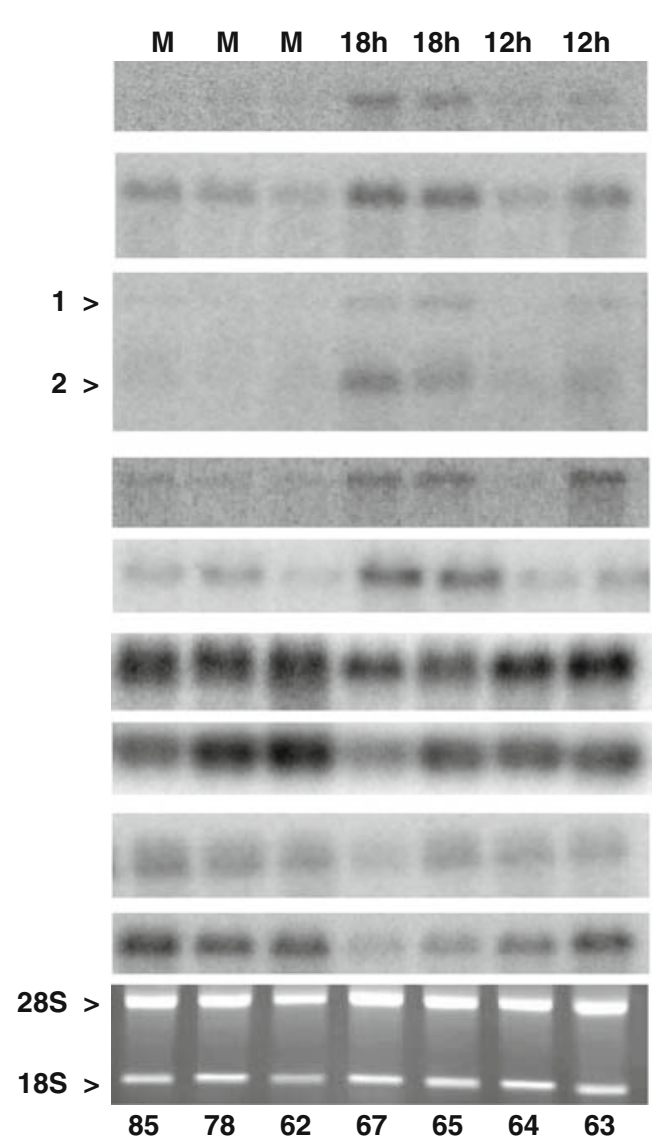

Fig. 2 Quantitative and qualitative validation of differential expression by Northern blot analysis. Left panel images of hybridized blots. $M$; uninfected piglets. Twelve hours and $18 \mathrm{~h}$; infected piglets. An ethidium bromide staining of one of the gels before blotting, showing porcine $28 \mathrm{~S}$ and $18 \mathrm{~S}$ ribosomal RNA bands, is shown at the bottom. Piglet numbers are listed beneath the images. Right panel the length

lowest possible false-discovery rate (FDR; based on SAM, [43]), i.e., $0.35 \%$ for the 18 -h comparison and $4.6 \%$ for the 12-h comparison, were selected for further analysis. Raising of the FDR to a maximum of $10 \%$ did not identify additional probes with a $\mathrm{FC}<0.28$ or $>3.6$ in either comparison. Selected probes were sequenced and annotated after blastn or blastx analysis (when not yet annotated). For each differential expressed probe, the mean FC calculated from the two dye-swap slides is presented in Table 2. When Cy3- and Cy5-labeled cDNA was prepared from the same uninfected RNA pool and simultaneously hybridized on the array, none of the probes that hybridized differentially in the 12- and 18-h comparisons hybridized differentially (results not shown). Six out of the nine probes that hybridized with a FC of 3.6-fold or more in the 12-h comparison (panel "higher in infected") also hybridized significantly more strongly in the 18-h comparison. For three of these probes (R14$\mathrm{R} 16)$, the ratio of differential expression further increased

\begin{tabular}{|c|c|}
\hline mRNA & $\begin{array}{c}\text { Length (kb) } \\
\text { NB / genbank (acc.na) }\end{array}$ \\
\hline GuanylateBinding Prot. 2 & $3.7 / 3.7$ (gi:30268253) \\
\hline Keratin 20 & $1.8 / 1.8$ (gi:27894336) \\
\hline $\begin{array}{c}\text { Spermidine / spermine -N1- } \\
\text { acetyltranferse } \\
1>3.6 / 3.5^{*} \text { (gi:47523773) } \\
2>1.6 / 1.3{ }^{*} \text { (gi:47523773) }\end{array}$ & 6.8 / 6.5 (gi:17648143) \\
\hline $\begin{array}{c}\text { Maltase glycoamylase } \\
\text { Caspase-3 }\end{array}$ & 2.8 / 2.6 (gi:14790118) \\
\hline Glutathion-S-transferase & $1.1 / 0.95$ (gi:47523831) \\
\hline CalbindinD-9k & 0.6 / 0.44 (gi:55742800) \\
\hline AldolaseB & $1.8 / 1.7$ (gi:40354204) \\
\hline I-FABP2 & $2.5 / 2.3$ (gi:10938019) \\
\hline
\end{tabular}

(kb) of mRNA transcripts was calculated by extrapolation of their mobility on a standard curve prepared using $28 \mathrm{~S}, 18 \mathrm{~S}$ and $5 \mathrm{~S}$ ribosomal RNA as length markers and compared to the length of human or porcine mRNAs posted in the NCBI RNA reference sequence genbank (acc. no.) or observed in the literature (*) [19]

with time. In contrast, only one probe (R1) hybridized significantly less strongly at both time points. Based on literature search and data mining, a tentative function was assigned for the genes identified by blast analysis (see Table 2). In addition, the FC (infected over uninfected) of genes which were also found to be regulated in a previous study by Cuadras et al. [13], i.e., $16 \mathrm{~h}$ after infection of human intestinal epithelial Caco-2 cells with rotavirus live virus vaccine RVV, is provided in parentheses in Table 2 after the annotations.

Probes coding for IFN- $\gamma$, TNF- $\alpha$, GM-CSF, and IL-2, 4 , 6,8 , and 10 were spotted on the array. However, the fluorescence intensity was not higher than the background threshold for any of these probes, indicating that mRNA concentrations of these cytokines (including IFN- $\gamma$ ) in infected and uninfected mucosal scrapings were too low to detect by microarray analysis, probably due to the relatively low percentage of cytokine-producing (immune) cells present in intestinal mucosa [6]. 


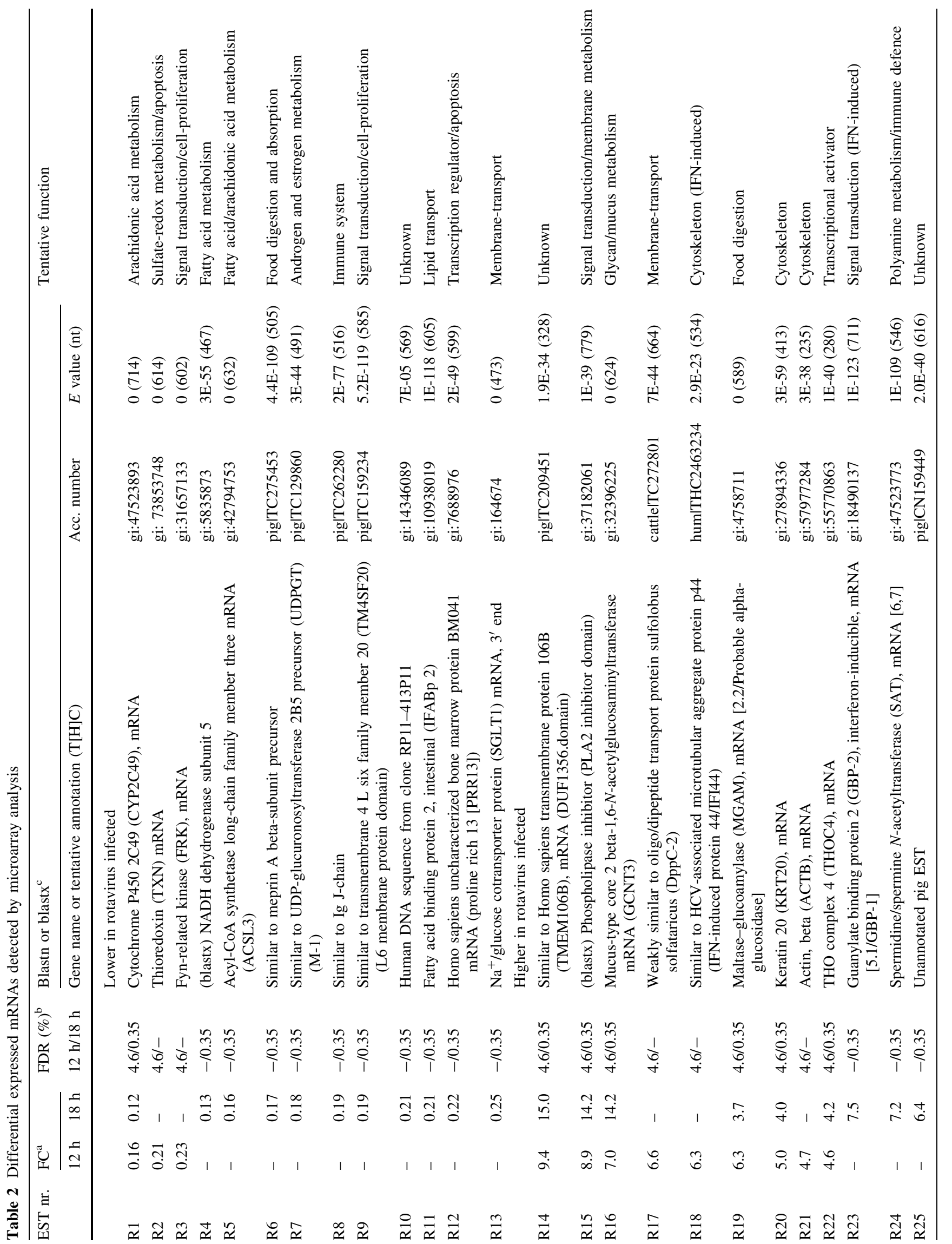




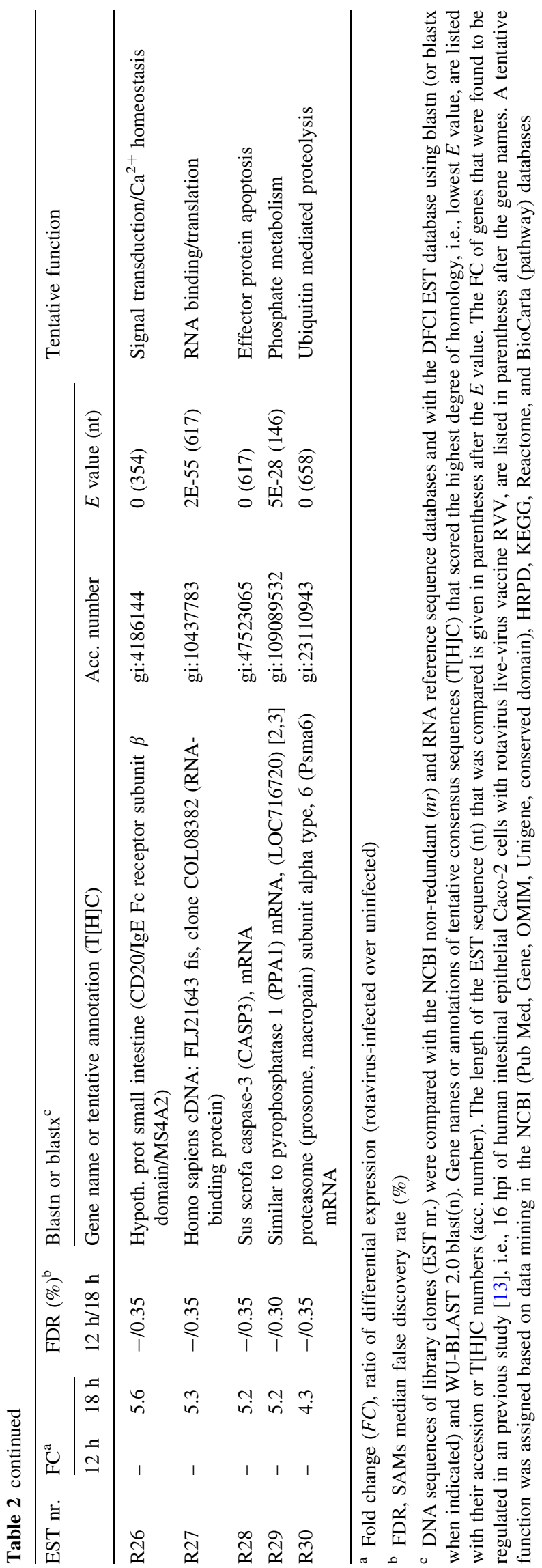

Northern blot analysis

Northern blots (NB) loaded with equal amounts of RNA from each of the piglets were hybridized with $\mathrm{P}^{32}$-labeled cDNA probes homologous to six differentially expressed mRNAs and to three mRNAs that were not identified as differentially expressed. For all nine mRNAs, the length of the transcript(s) detected on blots were comparable to the length of porcine or human mRNA reference sequences posted in the NCBI databank or reported in the literature. In accordance with array data, NB analysis showed that expression levels of GBP-2, KRT20, SAT, MGAM, and CASP3 mRNAs were significantly higher in both 18-hinfected piglets than in uninfected piglets. For all of these mRNAs, hybridization intensities for piglet 65 were nearly equal to that of piglet 67. GBP-2, KRT20, SAT, and MGAM mRNA expression was also up-regulated in infected piglet 63 , slaughtered at $12 \mathrm{hpi}$. This indicated that the response to rotavirus infection in this 12 -h piglet was comparable to the response observed in both 18-h piglets. However, no significant up-regulation of these mRNAs was observed in the other piglet slaughtered at $12 \mathrm{~h}$ (64), indicating that this piglet responded differently to the rotavirus infection than its $12-\mathrm{h}$ replicate and the two piglets slaughtered at $18 \mathrm{~h}$.

In accordance with array data, NB analysis showed that the expression level of IFABp 2 mRNA was significantly lower in 18-h-infected piglets than in uninfected piglets. For mRNAs that showed no significant differential expression on the arrays (glutathione-S-transferase, calbindin-D, and aldolase-B), no large differences in hybridization intensities were observed between uninfected piglets and the two piglets slaughtered $12 \mathrm{hpi}$ and one of the piglets slaughtered 18 hpi (65). However, significantly lower hybridization intensities were observed for calbindin-D and aldolase-B mRNAs for piglet 67 than for its $18-\mathrm{h}$ replicate.

\section{Discussion}

Using microarray analysis, we detected a set of genes that are differently expressed in rotavirus-infected jejunal mucosa compared to uninfected mucosa. For nine mRNAs, expression levels in individual piglets were analyzed by NB. These analysis confirmed the array data. In addition, NB analysis showed that one piglet slaughtered at $12 \mathrm{hpi}$ responded quite similarly to rotavirus infection as both 18$\mathrm{h}$ piglets did, whereas its 12 -h replicate did not, despite the fact that this latter piglet also showed an IFN- $\gamma$ mRNA response. In addition, 7 out of the 12 genes differentially expressed at $12 \mathrm{hpi}$ also reacted at $18 \mathrm{hpi}$. These results indicated that three out of four infected piglets responded 
quite analogously. Because we used a limited number of germ-free piglets per time point and measured responses in a mixed population of cells, we imposed stringent criteria for selection of genes ( $>3.6$-fold up- or down-regulation and a false-discovery ratio of less than 5\%). Using this approach, we minimized the chance of selecting genes hybridizing differentially solely due to inter-animal variation in gene expression and/or cell composition. However, such stringent selection criteria could have excluded the detection of more rotavirus-regulated genes, especially of genes regulated exclusively in specific types of cells that are present in low quantities in the jejunal mucosa. The different responsiveness of one of the 12-h piglets, however, obliged us to interpret our overall results carefully, especially, concerning the five genes that reacted solely at 12 hpi (TXN, FRK, DppC-2, IF144, and ACTB; see Table 2). Nevertheless, data mining revealed relevant relationships between these five genes, $18 \mathrm{~h}$ response genes, and processes known to be important for rotavirus pathogenesis.

Cuardras et al. [13] measured the transcriptional response in the human enterocyte cell line Caco-2, 1, 6, 12 and 16 hpi with Rhesus rotavirus live vaccine. Four genes up-regulated in our experiments (GBP-2, SAT, MGAM, PPA1) were also up-regulated 16 hpi in Caco-2 cells. Recently, Aich et al. [1] profiled the transcriptional response in surgically prepared jejunal loops from 1-dayold colostrum-deprived calves after $18 \mathrm{~h}$ of perfusion with bovine rotavirus (BRV). Several genes for which we detected more than 3.6-fold up- or down-regulation (TXN, NADH5, SGLT1, ACTB, SAT, CASP3, and PPA1) were also present on the cDNA array they used (NCBI GEO acc. number GPL325). None of these genes showed a differential expression of twofold or more in their study. The different route of administration and virulence of the strain used, the digestive differences between the jejunum of omnivores and herbivores, and, in the case of the study of Cuardras et al., the various specialized cell-types present in the jejunum of living animals versus cultured colon-derived Caco-2 cells are probably responsible for the poor correspondence between these three studies.

Based on relevant literature and functional information in databanks, we assigned a function and a possible type(s) of cell(s) responsible for expression for most of the genes on our list (Fig. 3). In this hypothetical model, information from existing models dealing with the pathogenesis of rotavirus infection [29, 39, 40] and the development and maintenance of the small intestinal epithelium [20] were used to fit in our data. Possible functions of these genes in relation to processes and pathways known to be important for rotavirus pathogenesis are discussed below.
Electrolyte homeostasis and malabsorption

Measurements of villus length indicated that considerable numbers of epithelial cells were lost from the tip of the villi, including (infected) mature enterocytes. In part, down-regulation of genes involved in transport of ions and nutrients over the membranes of mature enterocytes, like meprin A, SGLT1, and IFABp2, may be a direct result of this loss. In another part, replication of rotavirus in enterocytes imbedded in the epithelial layer could have down-regulated transcription of these genes. This may also be the case for other down-regulated genes from our list, especially for genes detected only at 18 hpi (R4-R13, Table 2). In addition to down-regulation of SGLT1, IFABp2, and meprin A, we observed up-regulation of two other genes that may affect the absorptive and digestive function of the intestine: a gene coding for a protein carrying a $\mathrm{Ca}^{2+}$-permeable cation channel CD20/IgE Fc receptor subunit $\beta$ domain (MS4A2) and a gene homolog to a bacterial oligo/dipeptide permease (DppC-2). It is tempting to link up-regulation of MS4A2 directly to NSP4induced enhancement of $\mathrm{Ca}^{2+}$ permeability of the plasma and ER membranes in intestinal epithelial cells [29, 40]. Likewise, up-regulation of the DppC-2 homolog may be related to enhanced laminal secretion of peptides and amines by uninfected epithelial cells, a process believed to be triggered by raised $\left[\mathrm{Ca}^{2+}\right]_{\text {cyt }}[40]$. Characterization of these porcine transcripts/proteins is needed to provide further insight in the role of these genes in rotavirus pathogenesis. The same applies for the TMEM106B gene. This gene showed the highest level of up-regulation. So far, only a DUF1356 protein domain with unknown function has been predicted in TMEM106B.

\section{Cell fate and repair of damaged epithelium}

Recently, it was reported that rotavirus infection in infant mice induced apoptosis in vivo [7]. Although DNA analysis showed that the majority of cells present in infected mucosal scrapings were not apoptotic, we observed upregulation of the apoptosis effector protein CASP3. This suggests that programmed cell death in the epithelial layer was stimulated by rotavirus infection. NB analysis detected a considerable level of CASP3 mRNA expression in uninfected mucosal scrapings. This constitutive expression of CASP3 is, most likely, related to the process of maintenance of the absorptive status of the intestinal epithelial layer. A process in which mature enterocytes continually die due to apoptosis and are replaced by differentiating cells migrating from surrounding crypts to the tip of the villi [20]. In contrast to mature enterocytes, an in vivo study in mice showed that goblet cells are largely spared from apoptosis in rotavirus-infected mice [8]. Moreover, 


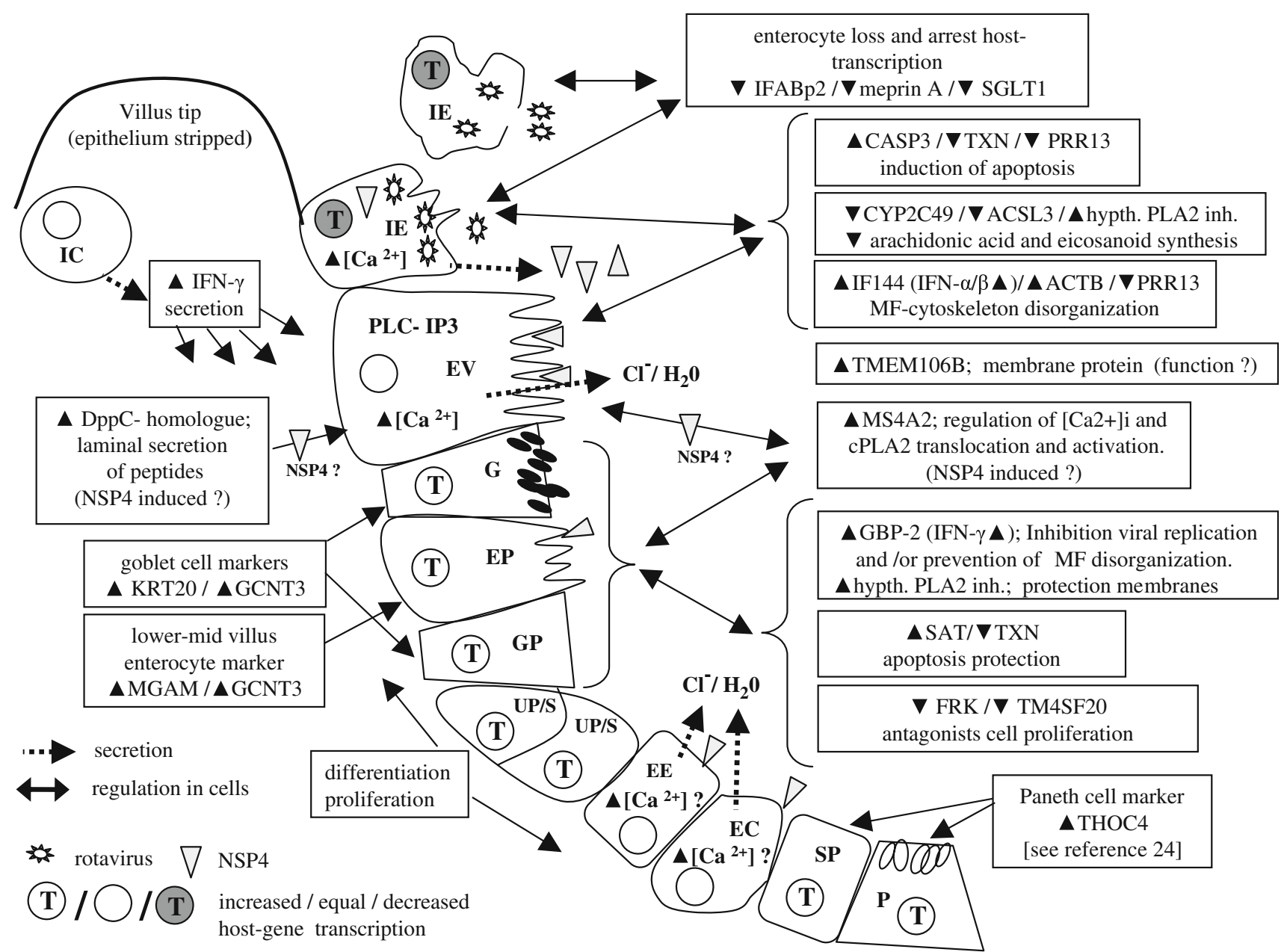

Fig. 3 Hypothetical model for up- and down-regulation of genes in the jejunum of rotavirus-infected germ-free piglets. Filled triangle or inverted filled triangle: up- or down-regulation. IFN filled triangle; IFN-induced. IC immune cells (neutrophils, macrophages, $T$ lymphocytes, dendritic cells, etc.), $I E$ rotavirus-infected enterocyte, $E V$ mature enterocyte villus, $E E$ enteroendocrine cell, $E P$ enterocyte

migration of goblet cells from the crypt to the tips of the villi was stimulated in these mice. We found up-regulation of the goblet cell marker gene KRT20 [51] and the lower and mid-villus immature enterocyte marker gene MGAM [42]. This could indicate that transcriptional activity in both of these cell types was promoted. Stimulation of apoptosis in rotavirus-infected enterocytes and higher proliferation/differentiating activity in goblet cells and immature enterocytes could be a coordinated response of the jejunum to remove infected enterocytes and overlay villus tips with fresh enterocytes, goblet cells, and mucus layer. We did not detect genes on our array that were directly associated with cell-cycle progression/arrest. However, down-regulation of the nuclear kinase FRK (an antagonist of cell proliferation) and TMS4F20 may be associated indirectly with this process. In humans, TMS4F20 is strongly homologous to TM4SF4, a protein progenitor (immature), $E C$ enterocyte crypt, $G$ (granular) goblet cell, $G P$ goblet cell progenitor, $S P$ secretory progenitor, $P$ paneth cell, $U P / S$ uncommitted progenitor/potential stem cell, $M F$ microtubule filament. Abbreviations for genes are provided in Table 2. Information about the Paneth cell marker THOC4 is provided in reference [24]

that reduced the ability of the crypt cell line HT29 to proliferate [48].

Several other genes that may play a role in cell death and repair were regulated. SAT was up-regulated, and TXN and PRR13 were down-regulated. For this later protein, reduced expression in cells was correlated with increased sensitivity to taxane-induced cell death, a caspase-independent process characterized by the polymerization of tubulins to extraordinarily stable microtubules $[27,30]$. TXN is the major carrier of redox potential in cells, and it is crucial for the defence of cells against oxidative-stressmediated apoptosis. TXN also regulates gene expression by increasing binding of redox-sensitive transcription factors like p53 [44], NF- $\kappa \mathrm{B}$ [25], and the Nrf-2/polyaminemodulated factor-1 (PMF-1) transcription factor complex to DNA. Overexpression of TXN in human breast cells decreased DNA binding of the Nrf-2/PMF-1 complex and 
inhibited SAT expression [23]. Therefore, up-regulation of SAT gene expression at $18 \mathrm{hpi}$ may be directly related to down-regulation of TXN at $12 \mathrm{hpi}$. SAT is a rate-limiting enzyme in spermine/spermidine metabolism. Acetylation of these polyamines by SAT promoted their degradation and excretion [46]. Recently, it was reported that depletion of polyamines suppresses apoptosis in normal intestinal epithelial cells by AKT-kinase-mediated inhibition of CASP3 activity [50]. NB analysis showed that the increase in SAT mRNA expression coincided with the goblet cell marker KRT20. Therefore, it would be interesting to determine whether SAT expression in goblet cells can be stimulated by rotavirus infection and whether it plays a role in protecting these cells from apoptosis [8]. Interestingly, it was recently demonstrated that RNA viruses can directly modulate polyamine metabolism by regulation of SAT transcription and splicing [36].

Lipid metabolism and membrane integrity

A most interesting gene that we found more than tenfold up-regulated codes for an as yet not-well-characterized hypothetical human protein (LOC646627) carrying a phospholipase A2 inhibitor domain (PLA2-inh). The magnitude and kinetics of up-regulation of this gene corresponded exactly with GCNT3, suggesting that this gene was expressed in the same types of cells as GCNT3, most likely mucus-producing goblet cells and/or differentiating (immature) enterocytes. The amino acid sequence translated from our PLA2-inh EST showed an overall amino acid identity of $56 \%$, and all cysteines aligned perfectly with cysteines of the human LOC646627 protein and of other proteins that bear a typical PLA2-inh domain. PLA2s comprise a diverse family of cytosolic and secreted enzymes that hydrolyze membrane phospholipids to free fatty acids. They play an important role in many exogenous and intracellular processes, ranging from fatty acid metabolism and lysis of membranes to the synthesis of arachidonic acid (A-acid), an essential precursor for the production of inflammatory mediators such as eicosanoids. Secreted PLA2s are calcium-dependent enzymes. Cytosolic PLA2s (cPLA2) can also be calcium-independent. A moderate increase in $\left[\mathrm{Ca}^{2+}\right]_{\mathrm{cyt}}$ mediated translocation of calcium-dependent cPLA2 to intracellular membranes where it hydrolyses phospholipids to A-acid [12]. A similar effect was observed after activation of the MS4A2 calcium-permeable cation channel (up-regulated here at $18 \mathrm{hpi}$, see above) on the surface of mast cells [14]. Perhaps, enhanced expression of a PLA2-inh in our study may be a countermeasure of specific intestinal epithelial cells to normalize and/or inhibit PLA2 enzyme activity in response to extra- and intracellular changes in $\left[\mathrm{Ca}^{2+}\right]$ evoked by rotavirus replication, either to protect specific cells from extra- and intracellular membrane-damage or to negatively regulate A-acid production. With respect to the latter process, we observed down-regulation of the enzymes CYP2C39 and ACSL3, which both utilize A-acid acid as substrate. Interestingly, the capsid protein of parvovirus possesses PLA2 activity [49], and HMCV particles carry a cell-derived PLA2 activity [2]. For both viruses, PLA2 activity appeared to be essential for infectivity.

IFN response and innate defense

Our results showed that IFN- $\gamma$ mRNA expression in the jejunum of infected piglets peaked around $12 \mathrm{hpi}$ and tended to decline beyond this time point (see Fig. 1). This suggests that IFN- $\gamma$ was produced for a short period. Recently, Aich et al. [1] measured the mRNA expression levels of several cytokines in jejunal loops perfused for $18 \mathrm{~h}$ with BRV. However, they observed no IFN $-\gamma$ mRNA response. Because our orally administered rotavirus needed time to reach the jejunum, our $18 \mathrm{~h}$ infection period represents a shorter period than $18 \mathrm{~h}$ of perfusion. After $18 \mathrm{~h}$ of perfusion, expression of IFN- $\gamma$ mRNA may have dropped to normal levels. Interestingly, they did detect a rotavirus-induced IL-6 (alias IFN- $\beta 2$ ) mRNA response at 18 hpi [1]. Recent studies showed that the interplay between IFN-gamma and IL-6 controls the influx and clearance of neutrophils and, subsequently, the transition to a more sustainable influx of mononuclear cells during acute inflammation [21, 31]. Therefore, it would be interesting to study which immune cells produce IFN- $\gamma$ and IL-6 and whether an orchestrated action of these cells regulates an influx of vital immune cells in the jejunum after rotavirus infection.

The IFN- $\gamma$-inducible GBP-2 gene was up-regulated 18 hpi. Overexpression of GBP-1 and GBP-2 in HeLa cells and NIH 3T3 cells abrogated the cytopathogenic effect mediated by VSV and EMCV, respectively, by an unknown mechanism [3,11]. Furthermore, it was shown that expression of murine GBP-2 in NIH $3 \mathrm{~T} 3$ cells neutralized the cytotoxic effect of the taxane drug Paclitaxel [4]. This drug specifically stimulates polymerization of tubulins to extraordinarily stable microtubules. These stable microtubules interfere with the function of normal microtubule filaments and inevitably induce cell death [4]. The reduced expression of PRR13 we observed (discussed above) may be an indication that the formation of extraordinarily stable microtubules in intestinal epithelial cells actually takes place in response to rotavirus infection. In fact, several studies have shown that rotavirus infection induces disorganization of the cytoskeleton network and microtubule filaments in enterocytes [9, 10, 26]. Moreover, we also observed the up-regulation of the 
IFN- $\alpha / \beta$-inducible gene IFI44, a cytosolic protein associated with microtubular structures, and the cytoskeleton gene ACTB. Therefore, enhanced expression of GBP-2 in specific intestinal epithelial cells could contribute to a cellular mechanism(s) that impairs and/or prevents disorganization of the microtubule filaments.

\section{Concluding remark}

Further in vivo studies are needed to determine whether the genes identified in this study are representative for an intestine with a normal microflora. If so, more focussed studies involving in situ hybridization and immuno-histology may specify where along the crypt-villus axis and in which type of epithelial (or immune) cells elevated or reduced expression of these genes is induced.

Acknowledgments The authors would like to thank Arie Hoogendoorn for his assistance in the animal experiment.

Open Access This article is distributed under the terms of the Creative Commons Attribution Noncommercial License which permits any noncommercial use, distribution, and reproduction in any medium, provided the original author(s) and source are credited.

\section{References}

1. Aich P, Wilson HL, Kaushik RS, Potter AA, Babiuk LA, Griebel PJ (2007) Comparative analysis of innate immune responses following infection of newborn calves with bovine rotavirus and bovine coronavirus. J Gen Virol 88:2749-2761

2. Allal C, Buisson-Brenac C, Marion V, Claudel-Renard C, Faraut T, Dal Monte P, Streblow D, Record M, Davignon JL (2004) Human cytomegalovirus carries a cell-derived phospholipase A2 required for infectivity. J Virol 78:7717-7726

3. Anderson S, Carton J, Lou J, Xing L, Rubin BY (1999) Interferon-induced guanylate binding protein-1 (GBP-1) mediates an antiviral effect against vesicular stomatitis virus and encephalomyocarditis virus. Virology 256:8-14

4. Balasubramanian S, Nada S, Vestal D (2006) The interferoninduced GTPase, mGBP-2, confers resistance to paclitaxelinduced cytotoxicity without inhibiting multinucleation. Cell Mol Biol (Noisy-le-grand) 52(1):43-49

5. Ball JM, Tian P, Zeng CQ-Y, Morris AP, Estes MK (1996) Agedependent diarrhea induced by a rotavirus nonstructural glycoprotein. Science 272:101-104

6. Bigger CB, Guerra B, Brasky KM, Hubbard G, Beard MR, Luxon BA, Lemon SM, Lanford RE (2004) Intrahepatic gene expression during chronic hepatitis $\mathrm{C}$ virus infection in chimpanzees. J Virol 78:13779-13792

7. Boshuizen JA, Reimerink JHJ, Korteland-Van Male AM, Van Ham VJJ, Koopmans MP, Buller HA, Dekker J, Einerhand AWC (2003) Changes in small intestinal homeostasis, morphology, and gene expression during rotavirus infection of infant mice. J Virol 77:13005-130016

8. Boshuizen JA, Reimerink JHJ, Korteland-Van Male AM, Van Ham VJJ, Bouma J, Gerwig GJ, Koopmans MPG, Dekker J,
Einerhand AWC (2005) Homeostasis and function of goblet cells during rotavirus infection in mice. Virology 337:210-221

9. Brunet JP, Cotte-Laffitte J, Linxe C, Quero AM, GeniteauLegendre M, Servin AL (2000) Rotavirus infection induces an increase in intracellular calcium concentration in human intestinal epithelial cells: role in microvillar actin alteration. J Virol 74:2323-2332

10. Brunet JP, Jourdan N, Cotte-Laffitte J, Linxe C, GeniteauLegendre M, Servin AL, Quero AM (2000) Rotavirus infection induces cytoskeleton disorganization in human intestinal epithelial cells: implication of an increase in intracellular calcium concentration. J Virol 74:10801-10806

11. Carter CC, Gorbacheva VY, Vestal DJ (2005) Inhibition of VSV and EMCV replication by the interferon-induced GTPase, mGBP-2: differential requirement for wild-type GTP binding domain. Arch Virol 150:1213-1220

12. Chang WC, Nelson C, Parekh AB (2006) $\mathrm{Ca}^{2+}$ influx through CRAC channels activates cytosolic phospholipase A2, leukotriene $\mathrm{C} 4$ secretion, and expression of c-fos through ERK-dependent and -independent pathways in mast cells. FASEB J 20:2381-2383

13. Cuadras MA, Feigelstock DA, An S, Greenberg HB (2002) Gene expression pattern in Caco-2 cells following rotavirus infection. J Virol 76:4467-4482

14. Currie S, Roberts EF, Spaethe SM, Roehm NW, Kramer RM (1994) Phosphorylation and activation of $\mathrm{Ca}(2+)$-sensitive cytosolic phospholipase A2 in MCII mast cells mediated by highaffinity Fc receptor for IgE. Biochem J 304:923-928

15. De Groot J, Kruijt L, Scholten JW, Boersma WJ, Buist WG, Engel B, van Reenen CG (2005) Age, gender and litter-related variation in T-lymphocyte cytokine production in young pigs. Immunology 115:495-505

16. Dong Y, Zeng CQ, Ball JM, Estes MK, Morris AP (1997) The rotavirus enterotoxin NSP4 mobilizes intracellular calcium in human intestinal cells by stimulating phospholipase C-mediated inositol 1, 4, 5-trisphosphate production. Proc Natl Acad Sci USA 94:3960-3965

17. Estes MK (2001) Rotaviruses and their replication. In: Fields BN, Knipe DM, Howley PM (eds) Fields virology, vol 2. Lippincott/ The Williams \& Wilkins Co., Philadelphia, pp 1747-1786

18. Geenen PL, Dopfer D, van der Meulen J, De Jong MC (2005) Transmission of $\mathrm{F} 4+E$ coli in groups of early weaned piglets. Epidemiol Infect 133:459-468

19. Green ML, Blaeser LL, Simmen FA, Simmen RC (1996) Molecular cloning of spermidine/spermine N1-acetyltransferase from the periimplantation porcine uterus by messenger ribonucleic acid differential display: temporal and conceptus-modulated gene expression. Endocrinology 137:5447-5455

20. Hauck AL, Swanson KS, Kenis PJ, Leckband DE, Gaskins HR, Schook LB (2005) Twists and turns in the development and maintenance of the mammalian small intestine epithelium. Birth Defects Res C 75:58-71

21. Hurst SM, Wilkinson TS, McLoughlin RM, Jones S, Horiuchi S, Yamamoto N, Rose-John S, Fuller GM, Topley N, Jones SA (2001) Il-6 and its soluble receptor orchestrate a temporal switch in the pattern of leukocyte recruitment seen during acute inflammation. Immunity 14:705-714

22. Hulst MM, Panoto FE, Hoekman A, van Gennip HGP, Moormann RJM (1998) Inactivation of the RNase activity of glycoprotein $\mathrm{E}^{\text {rns }}$ of classical swine fever virus results in a cytopathogenic virus. J Virol 72:151-157

23. Husbeck B, Stringer DE, Gerner EW, Powis G (1999) Increased thioredoxin-1 inhibits SSAT expression in MCF-7 human breast cancer cells. Nat Med 5:1277-1284

24. Jansman AJM, Niewold TA, Hulst MM (2007) Inclusion of linseed and linseed expeller meal in piglet diets affects intestinal gene expression profiles. Livest Sci 108:23-25 
25. Jin DY, Chae HZ, Rhee SG, Jeang KT (1997) Regulatory role for a novel human thioredoxin peroxidase in NF-kappaB activation. J Biol Chem 272:30952-30961

26. Jourdan N, Brunet JP, Sapin C, Blais A, Cotte-Laffitte J, Forestier F, Quero AM, Trugnan G, Servin AL (1998) Rotavirus infection reduces sucrase-isomaltase expression in human intestinal epithelial cells by perturbing protein targeting and organization of microvillar cytoskeleton. J Virol 72:7228-7236

27. Lih C-J, Wei W, Cohen SN (2006) Txr1: a transcriptional regulator of thrombospondin-1 that modulates cellular sensitivity to taxanes. Genes Dev 20:2082-2095

28. Lundgren O, Timar-Peregrin A, Persson K, Kordasti S, Uhnoo I, Svensson L (2000) Role of the enteric nervous system in the fluid and electrolyte secretion of rotavirus diarrhea. Science 287:491495

29. Lundgren O, Svensson L (2001) Pathogenesis of rotavirus diarrhea. Microbes Infect 3:1145-1156

30. Mateo V, Brown EJ, Biron G, Rubio M, Fischer A, Deist FL, Sarfati M (2002) Mechanisms of CD47-induced caspase-independent cell death in normal and leukemic cells: link between phosphatidylserine exposure and cytoskeleton organization. Blood 100:2882-2890

31. McLoughlin RM, Witowski J, Robson RL, Wilkinson TS, Hurst SM, Williams AS, Williams JD, Rose-John S, Jones SA, Topley $\mathrm{N}$ (2003) Interplay between IFN-gamma and IL-6 signaling governs neutrophil trafficking and apoptosis during acute inflammation. J Clin Invest 112:598-607

32. Nabuurs MJ (1991) Etiological and pathogenic studies on postweaning diarrhea. Ph.D. thesis, State University of Utrecht

33. Nabuurs MJ, Hoogendoorn A, van Zijderveld-van Bemmel A (1996) Effect of supplementary feeding during the sucking period on net absorption from the small intestine of weaned pigs. Res Vet Sci 61:2-77

34. Niewold TA, Kerstens HH, van der Meulen J, Smits MA, Hulst MM (2005) Development of a porcine small intestinal cDNA micro-array: characterization and functional analysis of the response to enterotoxigenic $E$. coli. Vet Immunol Immunopathol 105:317-329

35. Niewold TA, Veldhuizen EJ, van der Meulen J, Haagsman HP, de Wit AA, Smits MA, Tersteeg MH, Hulst MM (2007) The early transcriptional response of pig small intestinal mucosa to invasion by Salmonella enterica serovar typhimurium DT104. Mol Immunol 44:1316-1322

36. Nikiforovaa NN, Velikodvorskajaa TV, Kachkob AV, Nikolaeva LG, Monastyrskayaa GS, Lukyanova SA, Konovalovab SN, Protopopovab EV, Svyatchenkob VA, Kiselevb NN, Loktevb VB, Sverdlov ED (2002) Induction of alternatively spliced spermidine/spermine N1-acetyltransferase mRNA in the human kidney cells infected by venezuelan equine encephalitis and tickborne encephalitis viruses. Virology 297:163-171

37. Obert G, Peiffer I, Servin AL (2000) Rotavirus-induced structural and functional alterations in tight junctions of polarized intestinal Caco-2 cell monolayers. J Virol 74:4645-4651
38. Parashar UM, Hummelman EG, Bresee JS, Miller MA, Glass RI (2003) Global illness and deaths caused by rotavirus disease in children. Emerg Infect Dis 9:565-572

39. Ramig RF (2004) Pathogenesis of intestinal and systemic rotavirus infection. J Virol 78:10213-10220

40. Ruiz MC, Cohen J, Michelangeli F (2000) Role of $\mathrm{Ca}^{2+}$ in the replication and pathogenesis of rotavirus and other viral infections. Cell Calcium 28:137-149

41. Tian P, Estes MK, Hu Y, Ball JM, Zeng CQ, Schilling WP (1995) The rotavirus nonstructural glycoprotein NSP4 mobilizes $\mathrm{Ca}^{2+}$ from the endoplasmic reticulum. J Virol 69:5763-5772

42. Traber PG, Yu L, Wu GD, Judge TA (1992) Sucrase-isomaltase gene expression along the crypt-villus axis of human small intestine is regulated at level of mRNA abundance. Am J Physiol 262:123-130

43. Tusher VG, Tibshirani R, Chu G (2001) Significance analysis of microarrays applied to the ionizing radiation response. Proc Natl Acad Sci USA 98:5116-5121

44. Ueno M, Masutani H, Arai RJ, Yamauchi A, Hirota K, Sakai T, Inamoto T, Yamaoka Y, Yodoi J, Nikaido T (1999) Thioredoxindependent redox regulation of p53-mediated p21 activation. J Biol Chem 274:35809-35815

45. Vellenga L, Egberts HJ, Wensing T, van Dijk JE, Mouwen JM, Breukink HJ (1992) Intestinal permeability in pigs during rotavirus infection. Am J Vet Res 53:1180-1183

46. Vujcic S, Halmekyto M, Diegelman P, Gan G, Kramer DL, Janne J, Porter CW (2000) Effects of conditional overexpression of spermidine/spermine N1-acetyltransferase on polyamine pool dynamics, cell growth, and sensitivity to polyamine analogs. J Biol Chem 275:38319-38328

47. Wang Y, Dennehy PH, Keyserling HL, Tang K, Gentsch JR, Glass RI, Jiang B (2007) Rotavirus infection alters peripheral T-cell homeostasis in children with acute diarrhea. J Virol 81:3904-3912

48. Wice BM, Gordon JI (1995) A tetraspan membrane glycoprotein produced in the human intestinal epithelium and liver that can regulate cell density-dependent proliferation. J Biol Chem 270:21907-21918

49. Zadori Z, Szelei J, Lacoste MC, Li Y, Gariepy S, Raymond P, Allaire M, Nabi IR, Tijssen P (2001) A viral phospholipase A2 is required for parvovirus infectivity. Dev Cell 1:291-302

50. Zhang HM, Rao JN, Guo X, Liu L, Zou T, Turner DJ, Wang JY (2004) Akt kinase activation blocks apoptosis in intestinal epithelial cells by inhibiting caspase- 3 after polyamine depletion. J Biol Chem 279:22539-22547

51. Zhou Q, Cadrin M, Herrmann H, Chen $\mathrm{CH}$, Chalkley RJ, Burlingame AL, Omary MB (2006) Keratin 20 serine 13 phosphorylation is a stress and intestinal goblet cell marker. J Biol Chem 281:16453-16461 